\title{
Integralidade e redes de cuidado: uma experiência do PET-Saúde/Rede de Atenção Psicossocial
}

Maria Lenz Cesar Kemper(a) Jessica Prado de Almeida Martins ${ }^{(b)}$

Sabrina Felipe Serra Monteiro ${ }^{(c)}$

Thaisa da Silva Pinto ${ }^{(d)}$

Fernanda Resende Walter ${ }^{(\mathrm{e})}$

Considerando que uma formação ampliada em saúde deve abarcar a complexidade intrínseca à noção de redes, este trabalho tem como proposta analisar a construção do cuidado em Saúde Mental em suas várias frentes. Uma atenção integral em saúde não se restringe ao acesso à rede formal de serviços, fazendo-se necessário acompanhar o percurso do usuário para incluir, no cuidado, as diferentes redes a ele pertinentes. Dentre essas, destacamos, além da rede formal de serviços em saúde, a rede familiar e a rede territorial e afetiva.

O paciente com sofrimento psíquico, por sua fragilidade no laço social e pelo estigma que a doença psiquiátrica carrega, vivencia, de maneira acentuada, os rebatimentos de uma falta de articulação entre as distintas esferas de cuidado. Um cuidado em saúde mental não pode se restringir a uma ação protocolar, só faz sentido se incluir a realidade, o cotidiano e a situação social, familiar e afetiva do sujeito. Com o intuito de propor uma formação que considere a complexidade dessas diversas instâncias, o PET-Saúde/Rede de Atenção Psicossocial: priorizando o enfrentamento do álcool, crack e outras drogas/ UFRJ apresenta um campo teórico e prático, não apenas para os estudantes de graduação de diferentes cursos que participam do projeto, mas, também, para as equipes envolvidas, de reflexão sobre os constantes desafios para aqueles que atuam na construção do cuidar em Saúde Mental.

O PET - Programa de Educação pelo Trabalho - tem como objetivo oferecer uma formação ampla e interdisciplinar aos estudantes de graduação por meio da inserção no campo de atuação profissional. Especificamente este PET, ao qual se refere o presente texto, é inspirado na experiência da equipe do Professor Emerson Merhy na rede de Saúde Mental de Campinas ${ }^{1}$, que propunha repensar o cuidado a partir da compreensão dos acessos e barreiras. O PET-Saúde/ Rede de Atenção Psicossocial: priorizando o enfrentamento do álcool, crack e outras drogas/UFRJ conta com quatro campos na cidade do Rio de Janeiro: dois CAPSad III, que são unidades de saúde mental especializadas em atender os dependentes de álcool e drogas; um Consultório na Rua, que oferta atenção integral à saúde a pessoas que vivem nas ruas, e um CAPS II, destinado a adultos que sofrem de transtornos mentais graves, serviço ao qual esta experiência se refere especificamente. (a) Secretaria Municipal de Saúde do Rio de Janeiro. Rua Afonso Cavalcanti, 455, Superintendência de Saúde Mental, Cidade Nova. Rio de Janeiro, RJ, Brasil. 20211-110. mariakemper@hotmail.com

${ }^{(b, c)}$ Instituto de Psiquiatria, Universidade do Brasil (IPUB). Rio de Janeiro, RJ, Brasil.prado.ms@gmail.com; sabrina.serra23@yahoo.com.br

(d) Faculdade de Medicina, Departamento de Terapia Ocupacional, Universidade Federal do Rio de Janeiro. Rio de Janeiro, RJ, Brasil. thaisasp@yahoo.com.br

(e) Faculdade de Medicina, Departamento de Terapia Ocupacional, Universidade Federal do Rio de Janeiro. Rio de Janeiro, RJ, Brasil. fernanda_resende_@hotmail.com 
A proposta do PET de abertura de um espaço de formação, de pesquisa e de exercício crítico vem suscitando, na equipe envolvida neste Projeto, uma reflexão sobre o cuidado, trazendo questionamentos que incitam a troca com outras equipes de saúde mental e de saúde, com estudantes da área e com trabalhadores que pensam as políticas públicas, além de parceiros de rede. A participação em Congressos, em Encontros de PET, em reuniões sobre o tema vem mostrando quanto essa troca é produtiva, o que culminou com este relato de experiência.

A metodologia adotada neste Projeto é a do caso traçador, por meio do acompanhamento criterioso de casos de alta complexidade no serviço, ou seja, usuários que demandam várias redes e que provocam dificuldades e impasses em seu cuidado. A proposta da pesquisa é pensar a saúde sob a perspectiva da integralidade, ampliando a compreensão sobre as formas de cuidar ao incluir as redes não formais do usuário no desenho de seu projeto terapêutico.

Para tanto, a metodologia deste PET rompe com os métodos tradicionais científicos, convidando o pesquisador a estar no território e no cotidiano do usuário, a afetar e ser afetado. Neste tipo de estudo, o pesquisador está aberto à experiência do encontro com o objeto, é ativo em uma prática que se constrói no próprio fazer, que não tem metas predeterminadas. Dessa forma, tanto pesquisador quanto pesquisado não são neutros ou independentes, sujeito e objeto não são posições estanques; ao contrário, influenciam-se mutuamente, estando a pesquisa em constante construção².

A pesquisa toma como referência a cartografia, ou seja, o mapeamento, a partir do acompanhamento do usuário, de suas redes (incluindo, aqui, as redes formal, familiar e existencial), permitindo conhecer qual é o movimento que ele faz. Cartografar vai além de mapear o território físico, incluindo a escuta, feita com o usuário, familiar ou outras fontes, buscando entender quais são suas demandas, necessidades e movimentos nas redes pelas quais circula. Assim, pode ser valioso que a equipe de referência de um usuário esteja não só no serviço, mas, também, no seu território, fazendo contato com sua rede informal, conhecendo outras esferas de sua vida. Essa ampliação possibilita uma relativização da perspectiva, comum a uma proposta de atenção limitada à rede formal, de focar o cuidado no diagnóstico e na cura, o que reduz, muitas vezes, os pacientes a rótulos estigmatizantes. Conhecer o usuário em suas diversas redes oferece um novo olhar sobre as formas como ele se relaciona/é com o/no mundo3.

A partir dos novos olhares criados com a ajuda dos pacientes, outras possibilidades de vinculações e de tratamento surgem. Trata-se da construção de um saber com em vez de um saber sobre o paciente, propondo uma modalidade de compreensão que inclui as vicissitudes e singularidades de cada sujeito e que foge ao paradigma formal de cuidado, em geral prescritivo-normativo. A ideia é deslocar, da concepção de que possa haver um conhecimento superior, uma verdade absoluta sobre a doença e a saúde, passível de ser ensinada na academia e compreendida no campo teórico. O trabalho do pesquisador, nesse enquadre, é de atenção à experiência, estando ao lado do paciente e não sobre ele, incluindo-se no seu movimento. A prática deste PET vem mostrando quanto um plano de cuidado pode ser mais potente se incluir a experiência in loco, o território afetivo, o cotidiano do paciente. Conforme veremos com a ilustração de alguns casos, o trabalho fica mais rico quando considera instâncias plurais de cuidado - outros dispositivos da rede de saúde e da assistência (e, por vezes, da educação, da habitação etc.), a família e a rede informal (amigos, vizinhos, comerciantes locais etc.). Com frequência, esses possuem um maior contato com o paciente, que, muitas vezes, não comparece ao serviço.

A rede formal de cuidado é limitada não apenas pela dificuldade, tantas vezes presente, de vínculo e de adesão ao tratamento, mas, também, porque essa rede é restrita a um espaço físico, a um protocolo e, até mesmo, a um diagnóstico. Entretanto, a própria definição de saúde é ampla e inclui dimensões variadas, como preconiza a OMS (Organização Mundial da Saúde), que compreende saúde como "o completo estado de bem-estar físico, mental e social, e não simplesmente a ausência de enfermidade"4 (p. 2). A Lei Orgânica da Saúde, por sua vez, estabelece um conjunto de determinantes e condicionantes de saúde, afirmando que esta não é somente a ausência de doença, e considerando, portanto, dimensões como moradia, trabalho e saneamento básico 5 .

O foco na doença, e não no sujeito como um todo, ainda é uma prática comum, apesar de a integralidade ser princípio básico do funcionamento do SUS. Esse princípio, que inclui promover e 
prevenir a saúde e buscar uma articulação das diversas redes para oferecer um cuidado ampliado, muitas vezes não encontra eco na realidade dos serviços de saúde. O exercício de uma prática crítica, atenta à construção cotidiana do cuidar, é tarefa difícil e, infelizmente, rara nas unidades de saúde, muitas vezes geridas por uma lógica focada em procedimento e produtividade.

Uma concepção de saúde fica muito limitada se não faz uma costura entre o planejamento e a prática cotidiana, entre o pensar e o fazer. Teoria e prática só fazem sentido quando se articulam. Nesse sentido, é fundamental que a formação em saúde ofereça uma experiência de reflexão crítica, incluindo tanto a dimensão teórica quanto a prática, e buscando uma aproximação entre as duas que compreenda a complexidade do cuidado em saúde. Por isso, cabe repensar o papel da Universidade, que não deve se restringir ao âmbito acadêmico, o qual se apresenta como lugar de referência de conhecimento e de promoção de um saber idealizado que, muitas vezes, não condiz com a realidade. Por o Sistema Único de Saúde ser recente (tem cerca de vinte anos apenas), há um enorme distanciamento entre o que é ensinado na universidade e a prática profissional, uma vez que muitos cursos tradicionais na área da saúde ainda não passaram por reformas curriculares que incluam teoria e prática no SUS e preceitos como a interdisciplinaridade e a atenção integral à saúde 6 . Assim, a formação tradicional, muitas vezes, limita-se a um saber distante do que o profissional irá encontrar no cotidiano do SUS, apresentando um conhecimento muito segmentado e especializado, com enfoque na doença. Se não há um olhar sobre o paciente como um todo, cria-se uma barreira para a construção de um cuidado integral? .

A proposta do PET advém dessa compreensão de que a formação profissional deve ser pautada numa integração entre teoria e prática, indo além da universidade e valorizando não apenas a dimensão técnica (conhecimento especializado), mas a social. A escolha de um CAPS - Centro de Atenção Psicossocial - como campo para este PET tem como objetivo incluir, na formação dos estudantes, essa perspectiva de um cuidado ampliado, territorial.

Os CAPS são dispositivos do SUS que consideram a integralidade, trabalham com equipe multidisciplinar e propõem uma atenção no território. Esses serviços são unidades especializadas em saúde mental cujo objetivo é o tratamento e a reinserção social de pessoas com transtornos mentais graves e persistentes. Os CAPS oferecem cuidados clínicos e atenção psicossocial, acolhendo aqueles que passam por sofrimentos psíquicos intensos e criando projetos terapêuticos como construções conjuntas entre pacientes, técnicos e familiares ${ }^{8}$.

O trabalho dos CAPS não poderia prescindir de uma articulação com a rede familiar que, em geral, constitui a primeira e mais presente instância de cuidado e, portanto, estrutura importante de acesso/barreira. O modo de organização familiar e as relações a ela inerentes possui rebatimentos concretos no cuidado com os usuários, tanto pela dimensão de suporte e solidariedade, quanto pelas dificuldades e dinâmicas patológicas. Nesse sentido, uma atenção integral em saúde mental não pode desconsiderar os cuidadores, que têm problemáticas, demandas e necessidades múltiplas e variadas, permeadas pelas conexões estabelecidas em suas relações sociais. Tais demandas, por vezes, buscam respostas que estão para além de como saber fazer/cuidar, pois pedem novas estratégias no manejo das situações apresentadas. Nesse sentido, é necessária uma leitura da realidade em que o paciente está inserido, que não se limita somente à questão do seu comprometimento psíquico.

São vários os aspectos que podem ser abordados em relação à rede familiar. Não se podem negligenciar: as dificuldades inerentes à lida com uma pessoa com um transtorno psiquiátrico, a ferida narcísica que representa ter um familiar com graves comprometimentos, o ideal de cura e de resgate da normalidade, o aspecto moral aí presente, a busca por controle, a solidão e o esgotamento etc. A inclusão de outras redes, atores e possibilidades de cuidado ameniza os sentimentos de culpa e frustração tão presentes em familiares sobrecarregados com a responsabilidade por um sujeito em sofrimento psíquico intenso. Um cuidado compartilhado, que inclua o território e as dinâmicas afetivas dos sujeitos, ajuda a desmistificar a obrigação de responder pelos cuidados dos pacientes que tantos familiares tomam para si. Aproximar-se da realidade dessas famílias, fazer parceria com os atores envolvidos na atenção aos pacientes, entender as referências e dinâmicas de laço social que os constituem são preciosos para se pensarem estratégias de cuidado potentes. 
A história de Allan ${ }^{(f)}$ demonstra que só foi possível criar um vínculo de tratamento mais efetivo quando a equipe passou a olhar de perto para a sua realidade familiar, o que permitiu resgatar sua história e seu lugar no mundo.

Allan, hoje com 39 anos, teve sua primeira crise psiquiátrica na adolescência, mas só iniciou um tratamento em saúde mental quando começou a fazer uso intensivo de drogas e álcool. Ele diz que se sente muito bem sob efeito das substâncias e, por isso, não precisa de ajuda, sem ter conseguido, ao longo de seis anos de acompanhamento psiquiátrico, manter uma frequência regular no CAPS. Sua relação com a irmã, atualmente principal figura de cuidado, é muito conflituosa. A mesma oferece um importante suporte (é na casa dela que ele come e toma banho, pois não há estrutura para isso em sua residência, além de ser ela quem administra a pensão do pai, única renda do paciente). Ela, entretanto, retém seus documentos, inclusive seu passe livre para gratuidade no transporte público, impedindo sua autonomia. Como ambos se mostravam resistentes às ofertas do CAPS como um espaço de escuta e de facilitação na administração do conflito entre eles, foi iniciado um trabalho no território, buscando-se outros atores envolvidos no cotidiano do Allan, como a agente comunitária de saúde e vizinhas. A partir da narrativa dessas outras fontes, descobriu-se que o quadro psiquiátrico do paciente se agravou com a morte de outra irmã que era a referência mais próxima de Allan, a qual não era mencionada nem por ele nem pela irmã. Além disso, com as visitas domiciliares, passou-se a dar mais atenção aos pedidos de Allan de que o CAPS deveria mesmo era tratar de seu irmão, este, sim, louco, segundo ele. Como a relação dos dois também era muito conflituosa, a equipe vinha entendendo que matricular o irmão no serviço representaria uma atitude invasiva e prejudicial ao vínculo, já frágil, de Allan com o CAPS. Foi na aproximação com a realidade familiar do paciente que se soube da gravidade do quadro de seu irmão, que, apesar de parecer articulado, faz uso da medicação de Allan, não consegue dar continuidade ao seu tratamento psiquiátrico ambulatorial e junta lixo em casa (o que torna a estrutura da residência de ambos ainda mais precária e atrai ratos e insetos). A partir da compreensão das dinâmicas familiares, do cuidado com a relação difícil entre Allan e sua irmã, e da atenção ao pedido do paciente de que matriculássemos seu irmão no CAPS, ele pôde se vincular à equipe do serviço e manter uma continuidade no seu tratamento.

Outra história ilustrativa da importância da ampliação das redes de cuidado é a de outra usuária do CAPS, a quem vamos chamar aqui de Solange. Ela tem uma relação extremamente conflituosa com a mãe, que lhe prendia num quartinho para impedir que ela saísse e, assim, fizesse uso de álcool e de drogas. Ao longo de oito anos de atendimento no CAPS, o relato em prontuário refere sempre uma impossibilidade de mudança de posição por parte da mãe, que parecia insistir em afirmar que Solange era um estorvo em sua vida e que nunca a desejara. A resistência da mãe à abordagem da equipe levou a uma compreensão de que não havia possibilidade de acesso à paciente, que não conseguia chegar no CAPS. A frustração das tentativas de trabalho com essa família, inclusive com outros atores diferentes da mãe, e a troca de profissionais de referência para o acompanhamento, acabaram resultando num desinvestimento no cuidado de Solange, que passou cerca de três anos afastada de seu tratamento.

A equipe do PET iniciou um trabalho com Solange a partir de seu território, trazendo outras dimensões de cuidado possíveis. Com o vínculo da equipe com a Agente Comunitária de Saúde (ACS) de referência, foi feito um mapeamento do território afetivo de Solange, percorrendo os locais por onde ela circula e (f) Os nomes dados aos pacientes são fictícios a fim de preservar sua identidade. 
conversando com pessoas presentes no seu dia a dia. Com isso, descobriu-se que Solange não só não estava "presa" em casa, como se supunha, mas estava vivendo com um companheiro e, tendo saído da casa da mãe, vinha mantendo com essa uma relação mais saudável. O fato de a equipe passar a estar no território, com visitas semanais ao local em que Solange reside, promoveu a criação de vínculo e uma reconstituição de sua história, descobrindo-se fatos bastante importantes de sua vida. Assim, com um investimento no cuidado a partir de uma perspectiva diferente da que se apresentava no interior do serviço de saúde mental, foi possível a aproximação de Solange com o CAPS, tendo ela passado a frequentá-lo semanalmente, desenvolvido importante relação com a equipe de referência e iniciado participação num espaço de geração de renda.

Entendemos que a aproximação fora do espaço físico do CAPS ampliou o olhar sobre o caso, possibilitando uma nova forma de cuidado. O território no qual o sujeito circula tem se mostrado uma importante e rica rede, que não deve ser desconsiderada em seu tratamento, e que só tem a somar às ofertas de cuidado por parte dos espaços institucionais (rede formal). A rede territorial é palco das relações sociais que constituem um sujeito, onde se produz/reproduz um conjunto de referências socioculturais, políticas, e econômicas, as quais qualificam seu cotidiano e sua inserção no mundo.

O acompanhamento dos casos traçadores do PET vem ratificando que o cuidado não pode se limitar ao campo da saúde. O caso de Luã aponta para isso, ao trazer uma problemática social que demonstra quanto a garantia de acesso aos serviços de saúde não é suficiente, mesmo que as questões clínicas sejam o foco da atenção. A história deste paciente choca pela coleção de diagnósticos graves: esquizofrenia, HIV, tuberculose e sífilis, além de ser usuário de crack. Ele vive em condições de insalubridade, tem moradia extremante precária, e não conta com renda. Assim, por mais que haja uma atenção e uma parceria efetiva das instâncias de cuidado em saúde de referência de Luã (Equipe de Saúde da Família, CAPS e Consultório na Rua), são igualmente importantes ações ligadas a políticas de habitação e de assistência social, além de parcerias com vizinhos, associação de moradores, projetos sociais e comércio local.

A inclusão da rede territorial do paciente mostra-se, assim, valiosa para a construção de um projeto terapêutico. A rede territorial abrange não só os serviços de saúde de referência, mas, também, outros locais pelos quais o sujeito transita, como: a comunidade, o bairro, o comércio local, as cenas de uso (no caso de usuários de drogas), os espaços de trabalho e geração de renda, locais de práticas esportivas e de lazer etc. Há uma dinâmica viva entre os sujeitos e os coletivos que habitam os espaços territoriais, e esta escapa à perspectiva física de uma ideia restrita de recorte geográfico. Assim, a noção de território que nos serve de referência para pensar as redes envolvidas no cuidado ampliado é complexa e inclui a relação singular do sujeito com o território que habita.

O conceito de território existencial definido pelos autores Deleuze e Guattari ${ }^{9}$ valoriza a experiência subjetiva, propondo que ele se constitui por meio da produção de sentidos. Trata-se de uma construção que forma identidades e delimita os espaços do que é interno ou externo ${ }^{10}$. $O$ entendimento de que todos os sujeitos habitam um território existencial supõe uma perspectiva de cuidado que atenda à singularidade de cada sujeito.

O que indica o perfil do cuidado não é o lugar físico onde se realiza o cuidado, mas o território existencial no qual o trabalhador se inscreve como sujeito ético-político, e que anda com ele onde ele estiver operando seu processo de trabalho. ${ }^{11}$ (p. 9)

A história de Gibson, um jovem surdo que tem diagnóstico de esquizofrenia, ilustra a importância da singularidade e quanto uma compreensão do caso sob a perspectiva da rede formal de atenção é limitada quando não se considera a realidade externa ao serviço de assistência. O prontuário de Gibson apontava para um empobrecimento de vida que não condizia com a vivacidade do CAPS, lugar de encontros, atividades e produção de cuidado. Gibson não saía de casa e, mesmo matriculado há quatro anos no serviço, havia ido poucas vezes para atendimento e sempre permanecia calado, olhando para baixo, sem fazer nenhum contato. A entrada da estagiária do PET no acompanhamento trouxe outra perspectiva ao caso quando iniciou visitas domiciliares ao paciente. Nestas, Gibson, desfazendo a imagem de uma pessoa tímida, limitada e isolada, fala bastante e com desenvoltura, e, assim, pôde 
contar que se sente muito mal quando está fora de casa (pois teme ser morto), mas que tem muitos amigos, convites e relações amorosas, apresentando um universo de sociabilidade via internet. Por meio da internet, ele namora, combina visitas a sua casa, faz e desfaz relações (em alguns meses de visitas, ele apresentou namoradas e até uma noiva, que lhe faziam companhia em sua casa). Gibson habita esse território virtual com maestria, transitando nas redes sociais de acordo com interesses e necessidades pessoais, produzindo seu território existencial, delimitando quem pode adentrar o espaço de dentro e o de fora, marcando as distâncias entre Eu e o Outro.

Por meio dessa compreensão ampliada de território, o PET-Saúde/Rede de Atenção Psicossocial: priorizando o enfrentamento do álcool, crack e outras drogas/UFRJ pôde, assim, construir um novo olhar para aqueles casos que eram considerados difíceis não só pela gravidade da doença e pelo seu manejo clínico, mas, também, pela falta de adesão ao tratamento e a ausência no espaço físico do CAPS.

O trabalho do PET tem oferecido, nesse sentido, um campo de formação que privilegia esta atenção ampliada não só para os estagiários do projeto, futuros profissionais de saúde, mas, também, para as equipes que os recebem. A metodologia de trabalho, que tem como base esse exercício de reconstruir e ressignificar o cuidado, vem trazendo movimentos e aberturas muito interessantes, também, para os profissionais envolvidos no projeto.

A disponibilidade e a vontade da equipe do PET de estar junto no acompanhamento dos casos propiciaram um novo estímulo para os profissionais que, muitas vezes, já tinham esgotado suas estratégias de tratamento com esses pacientes. A partir da pesquisa, foi possível uma outra forma de aproximação dos usuários elencados como casos traçadores, ampliando estratégias de cuidado.

Outro efeito do trabalho do PET foi o aumento da visibilidade dos casos, tanto na equipe do CAPS quanto em outros serviços e, em algumas situações, também nos territórios. O acompanhamento do PET suscitou diálogos sobre as demandas de cuidado dos pacientes e sobre as carências e necessidades da rede. Estratégias de implicação e responsabilização de outros dispositivos e compartilhamento de cuidado passaram a ser considerados, e muitos casos foram discutidos em reuniões de equipe, em supervisões de território fora do CAPS, e em visitas a outros dispositivos da rede. Nesses espaços, não se produz apenas uma ampliação do cuidado a um paciente específico, mas se tece uma rede de atenção, de trabalho e de solidariedade. Um exemplo é a discussão de um caso, que permitiu entender os limites da atuação de uma ACS, que, por não possuir conhecimento em saúde mental, não se sentia segura para atender individualmente um paciente. Com isso, foi feita uma conversa entre a estagiária do PET, a psicóloga do CAPS (referência do caso) e a ACS, na qual se costurou um trabalho conjunto, o que abriu a possibilidade de ela ir se sentindo, pouco a pouco, mais autorizada.

Uma última ilustração clínica traz mais um exemplo da importância da articulação das diferentes instâncias de rede para pensar um cuidado integral. Gabriel, um jovem que fala muito com as vozes que escuta (por conta de seu quadro de esquizofrenia), faz uso intensivo de álcool e cocaína. Embora muito querido na comunidade, ele assustava a vizinhança e sua ACS por parecer estar sempre muito drogado (SIC) devido a essa conversa quase incessante com as vozes. Foi a partir de encontros da equipe do PET com a equipe de saúde de família que esta entendeu seu adoecimento psiquiátrico e, podendo refletir sobre o a compreensão que se tinha daquele caso e do uso de drogas, conseguiu se aproximar do paciente. Esta equipe também se beneficiou desse encontro para saber da existência do CAPS e tirar dúvidas sobre doenças psiquiátricas, iniciando uma importante parceria. A equipe do CAPS, por sua vez, não conhecia a realidade social de Gabriel, que vive numa comunidade marcada pela forte presença do tráfico. O local em que as drogas são vendidas é muito próximo a sua casa, o que facilitava o uso abusivo de cocaína, que era oferecida em troca de favores ao tráfico e parecia 
representar uma forma de laço social. As visitas domiciliares, que impactaram os técnicos do CAPS pelo difícil acesso e intensa vigilância de traficantes de drogas, fortaleceram o vínculo da equipe com o paciente, a partir da compreensão de que o uso de drogas estava relacionado ao meio onde Gabriel vive. Com isso, Gabriel, que estava matriculado no CAPS há três anos, mas só chegava ao serviço muito raramente, passou a ir todos os dias ao CAPS. Este novo desenho de cuidado foi entendido pela equipe como uma redução de danos, pois, enquanto permanecia no serviço, não usava drogas. Hoje, Gabriel diminuiu significativamente sua frequência no CAPS, o que, num primeiro momento, causou preocupação. Entretanto, quando perguntado, Gabriel, que está menos invadido pelas vozes, esclareceu à estagiária do PET: "estou cuidando da minha vida".

Os usuários do CAPS circulam pelo território de uma forma singular, se conectam aos serviços de acordo com a maneira como se movimentam vida afora. Acompanhar o usuário pela rede, respeitando o seu movimento, faz parte do trabalho do clínico e possibilita a produção de relações e a construção de um cuidado.

Nesse sentido, o exercício de trazer para a prática profissional o papel de pesquisador, ou seja, uma análise crítica dos inúmeros fatores presentes numa determinada situação, contribui para uma reavaliação permanente do processo de cuidado, tecendo uma rede ampliada e adequada a cada situação particular. É nesta reinvenção e construção de projetos de cuidado singulares e que impliquem os sujeitos e atores envolvidos que se promove uma atenção efetiva e integral.

O cuidado em saúde mental segue os princípios da integralidade e tem, como ferramenta de trabalho, a relação. Ele deve contar, assim, com uma relação afinada entre os dispositivos de saúde, seus profissionais, o paciente e sua família. Uma boa relação entre um serviço de saúde e o seu entorno abre as portas para novas possibilidades de agenciamentos, mudando a relação da cidade com a doença, uma vez que produz trocas, desterritorializa e destrói barreiras. Dessa forma, cria-se acesso, permitem-se deslocamentos e reconfiguram-se territórios existenciais.

Entretanto, mesmo considerando a riqueza de perspectivas que o acesso ao território oferece, não são poucas as barreiras que se apresentam. Muitas vezes, a proposta de cuidado traçada não é viável, por conta do confronto com inúmeras dificuldades, como: a falta de articulação da rede; a carência de transporte para realizar visitas ao território, sua periculosidade e dificuldade de acesso; a resistência do paciente, familiares ou vizinhos a nos receberem ou conversarem conosco; a demanda das situações urgentes que se apresentam dentro do serviço e, tantas vezes, impedem a saída; a própria cultura da institucionalização, que tende a centrar o trabalho dentro das unidades etc.

Cuidar, ato complexo, pode ser entendido como um movimento de ocupação, preocupação, responsabilização e envolvimento, o que requer, do cuidador, conhecimento, sensibilidade e um estado de disponibilidade para o outro. Tal tarefa, desafiadora, fica mais possível e menos solitária se as variadas e ricas redes são incluídas nesse cuidado, compartilhando essa função de acompanhar os sujeitos, não como portadores de determinada doença, mas como sujeitos biológica, social e historicamente construídos.

Uma boa formação em saúde é aquela que atenta às diferentes conexões e potencialidades da rede, investindo em possibilidades de acompanhamento e vinculação tanto no serviço quanto no território. Nesse sentido, a formação deve implicar os profissionais de saúde numa perspectiva de integralidade, em que o cuidado engloba as diferentes necessidades, valoriza a autonomia e é compatível com a realidade social e afetiva de cada sujeito. Assim, se faz possível não apenas a qualificação da rede de cuidados na saúde pública, mas um enriquecimento de redes existenciais, favorecendo o exercício crítico e permitindo trazer, para o campo da atenção, os lugares de produção de vida, troca e encontros potentes, que são palco de novas possibilidades de cuidado e de cidadania. 


\section{Colaboradores}

As autoras (com suas respectivas apresentações) trabalharam de forma integrada, da seguinte maneira: Maria Lenz Cesar Kemper coordenou o trabalho e fez a redação final; Jessica Prado de Almeida Martins fez contribuições importantes ao texto e à redação final; Sabrina Felipe Serra Monteiro contribuiu com o texto-base que serviu de inspiração para o escrito. Thaisa da Silva Pinto fez contribuições relevantes ao texto; Fernanda Resende Walter fez contribuições ao texto.

\section{Referências}

1. Merhy EE, organizador. Pesquisa Saúde Mental: acesso e barreira em uma complexa rede de cuidado: o caso de Campinas. Campinas; 2011. [Relatório final CNPq, Processo 575121/2008 4].

2. Abrahão AL, Merhy EE, Cerqueira Gomes MP, Tallemberg C, Souza Chagas M, Rocha $M$, et al. O pesquisador IN-MUNDO e o processo de produção de outras formas de investigação em saúde. In: Cerqueira Gomes MP, Merhy EE, organizadores. Pesquisadores IN-MUNDO: um estudo da produção do acesso e barreira em saúde mental. Porto Alegre: Rede UNIDA; 2014.

3. Alvarez J, Passos E. Cartografar é habitar um território existencial. In: Passos E, Kastrup $\checkmark$, Escóssia L, organizadores. Pistas do método da cartografia: pesquisa-intervenção e produção de subjetividade. Porto Alegre: Sulina; 2009. p. 132-50.

4. World Health Organization. Constitution of the World Health Organization: basic documents. Genebra: World Health Organization; 1946.

5. Brasil. Lei n 8.080, de 19 de setembro de 1990. Dispõe sobre as condições para a promoção, proteção e recuperação da saúde, a organização e o funcionamento dos serviços correspondentes e dá outras providências. Diário Oficial União;Seção 1:18055-9.

6. Almeida $M$, organizador. Diretrizes curriculares nacionais para os cursos universitários da área da saúde. Londrina: Rede Unida; 2003.

7. Nascimento DDG, Oliveira MAC. A política de formação de profissionais da saúde para o SUS: considerações sobre a residência multiprofissional em saúde da família. Rev Min Enferm. 2006;10(4):435-9.

8. Ministério da Saúde (BR), Secretaria de Atenção à Saúde,. Departamento de Ações Programáticas Estratégicas. Saúde Mental no SUS: os Centros de Atenção Psicossocial. Brasília, DF: Ministério da Saúde; 2004

9. Deleuze G, Guattari F. Mil platôs: capitalismo e esquizofrenia. Rio de Janeiro: Editora 34; 1995.

10. Franco TB, Merhy EE. El reconocimiento de la producción subjetiva del cuidado. Salud Colectiva. 2011;7(1):9-20.

11. Yasui S. Rupturas e encontros: desafios da reforma psiquiátrica brasileira [tese]. Rio de Janeiro: Escola Nacional de Saúde Pública Sérgio Arouca da Fundação Oswaldo Cruz; 2006. 
O presente artigo aborda a formação em saúde a partir da experiência do PET- Saúde/ Rede de Atenção Psicossocial: priorizando o enfrentamento do álcool, crack e outras drogas, da Universidade Federal do Rio de Janeiro - UFRJ. Compreendendo o cuidado em saúde mental como uma prática integral que inclui redes variadas e complexas (formal, territorial e familiar), a metodologia deste PET se utiliza da cartografia, convidando o pesquisador a estar no território e no cotidiano do usuário. Assim, aposta-se numa formação ampliada dos alunos de graduação, ao se ofertar um campo de interlocução entre teoria e prática. Alguns casos são apresentados para ilustrar essa experiência, que visa a identificar e intervir na dinâmica das redes de cuidado. A ampliação da compreensão de rede e o mapeamento de territórios afetivos expandem as possibilidades de um cuidado integral, promovendo saúde e qualidade de vida.

Palavras-chave: Educação em saúde. Saúde mental. Assistência ao paciente.

\section{Comprehensive and care networks: experience in PET-Health/Health Attention Networks}

This paper addresses health education based on the experience of the PET-Health/ Health Attention Networks developed at the Rio de Janeiro Federal University (UFRJ). Understanding mental health care as a comprehensive practice that includes varied and complex networks (formal, territory, and family), this project used cartography, inviting the researcher to be in the territory and the patient's daily life. Thus, there is an investment in the expanded education of undergraduate students, offering a dialogue between theory and practice. Cases are presented to illustrate this experience, which aims to identify and intervene in the dynamics of care networks. Understanding the networks and identifying affective territories increases the possibilities of comprehensive care, promoting health and quality of life.

Keywords: Health education. Mental health. Patient care.

\section{Integración y redes de atención: una experiencia del PET-Salud/Redes de Atención Psicosocial}

Este artículo aborda la educación en salud, basándose en la experiencia del PET-Salud/ Redes de Atención Psicosocial: dando prioridad al enfrentamiento del alcohol, crack y otras drogas, de la Universidad Federal de Rio de Janeiro (UFRJ). Comprendiendo la atención en salud mental como una práctica integral que incluye redes distintas y complejas (formales, territoriales y familiares), utilizando la cartografía, invitando al investigador a estar en el territorio y en el cotidiano del usuario. Por lo tanto, se apuesta en una formación amplia de los alumnos de pregrado, ofreciendo un campo de interlocución entre teoría y práctica. Algunos casos son presentados para ilustrar esta experiencia, que busca identificar e intervenir en la dinámica de las redes de atención. Mejorando esa comprensión de la red y caracterizando los territorios afectivos, se amplían las posibilidades de atención integral, promoviendo salud y calidad de vida.

Palabras clave: Educación en salud. Salud mental. Atención al paciente. 
